\title{
Panax ginseng Extract Modulates Cerebral Damage Caused by Gamma Irradiation in Male Albino Rats
}

\author{
Shereen Mohamed El kiki and Shereen Mohamed Galal ${ }^{\#}$ \\ Health Radiation Research Department, National Center for Radiation Research and \\ Technology (NCRRT), Atomic Energy Authority (AEA), PO Box 29, Nasr City, Cairo, \\ Egypt.
}

\begin{abstract}
THIS STUDY is designed to investigate the protective effect of aqueous Panax ginseng extract against acute brain damage induced by gamma irradiation in rats. Animals were sacrificed $24 \mathrm{~h}$ post-whole body gamma irradiation (6Gy). The results revealed oxidative injury denoted by a significant increase in the levels of malondialdehyde (MDA) associated to a significant decrease in the level of reduced glutathione (GSH), and superoxide dismutase (SOD) and catalase (CAT) activities in brain tissues. The administration of Panax ginseng at a dose of $100 \mathrm{mg} / \mathrm{kg}$ body weight for 7 consecutive days before irradiation has significantly attenuated the severity of oxidative stress. Furthermore, Panax ginseng has significantly improved the decrease recorded in the level of the neurotransmitters serotonin (5-HT), dopamine (DA), norepinephrine (NE) and acetylcholine (Ach) induced by gamma irradiation in brain tissue. The oral administration of ginseng extract prior to irradiation has attenuated also a significant decrease in serum asymmetric dimethyl arginine (ADMA) as well as a significant increase in serum nitric oxide (NO) compared with the irradiated group. The histopathological and immunohistochemical examination substantiate the aforementioned amelioration in the biochemical parameters. In conclusion, the Panax ginseng extract might alleviate the oxidative brain damage and the alteration of neurotransmitters induced by gamma-irradiation in rats.
\end{abstract}

Keywords: Panax ginseng, Gamma irradiation, Oxidative stress, Neurotransmitters.

\section{Introduction}

Radiation damage is largely caused by the overproduction of reactive oxygen species (ROS), including superoxide anion $\left(\mathrm{O}_{2}^{\bullet-}\right)$, hydroxyl radical $(\bullet \mathrm{OH})$ and hydrogen peroxide $\left(\mathrm{H}_{2} \mathrm{O}_{2}\right)$ that overwhelm the levels of antioxidants resulting in oxidative stress. The most important consequences of oxidative stress are lipid peroxidation, protein oxidation and depletion of antioxidant elements. If these damages are irreparable then injury, mutagenesis and carcinogenesis accelerated senescence and cell death can occur (Spitz et al., 2004).

Efficient defense and repair mechanisms exist in living cells to protect against oxidant species. Superoxide dismutase (SOD) catalyzes the reduction of $\mathrm{O}_{2}$ to $\mathrm{H}_{2} \mathrm{O}_{2}$, the majority of which is broken down to oxygen and water by catalase (CAT). In addition to CAT, glutathione peroxidase in the presence of an adequate amount of reduced glutathione (GSH) can also break down $\mathrm{H}_{2} \mathrm{O}_{2}$ (Sun et al., 1998). However, under abnormal conditions such as exposure to ionizing radiation, the antioxidant defense system is not fully operative.

Increased production of ROS can compromise essential cellular functions and probably contribute to brain injury (Starkov et al., 2004). Experimental evidence revealed that the brain displays numerous biochemical and functional alterations after exposure to ionizing radiations (Loganovsky \& Yuryev, 2004). Since the monoamines; serotonin (5-HT), dopamine (DA) and norepinephrine (NE) play critical roles in consciousness, mood, thought, motivation, cognition, perception, and autonomic responses. The alteration in the metabolism of these monoamines leads to brain dysfunction (Jia et al., 2010). 
Nitric oxide (NO), a free gaseous signaling molecule, is involved in the regulation of the cardiovascular, nervous and immune system. The neurotransmitter function of nitric oxide is dependent on dynamic regulation of its biosynthetic enzyme, nitric oxide synthase (NOS). There are three types of NOS, neuronal nitric oxide synthase (nNOS), endothelial nitric oxide synthase (eNOS) and inducible nitric oxide synthase (iNOS) (Zhou \& Zhu, 2009). Asymmetric di-methyl arginine (ADMA) is a by-product of amino acid metabolism that can interfere with nitric oxide synthesis by competitive inhibition of endothelial nitric oxide synthase (eNOS) (Langer \& Shah, 2005). Increased levels of ADMA are associated with endothelial dysfunction. ADMA may contribute to brain dysfunction in patients with Alzheimer's disease and stroke (Selley, 2003). Also, elevated ADMA levels found in blood of human cirrhotic patients correlated well with cognitive symptoms and brain biochemical abnormalities (Bajaj et al., 2013). Although the neuroprotective mechanism of Ginseng on the central nervous system (CNS) is unclear there is evidence to suggest that it may possibly be involved in synaptic plasticity, the calcium cascade, and neuronal apoptosis (Cheng \& Zhang, 2005 and Wenbin et al., 2015).

Ginseng, the root and rhizome of Panax ginseng, a well-known medicinal herb in traditional Asian medicine grows in China and Korea. It was reported to possess a variety of beneficial biological actions that include anti-carcinogenic, anti-diabetic and anti-inflammatory as well as cardiovascular protection and neuroprotection (Jung et al., 2005 and Xiang et al., 2008). The main active ingredients of Panax ginseng are ginsenosides which facilitated neurotransmission in the brain (Xue et al., 2006 and Liu et al., 2010). In addition, ginsenosides have been reported to improve central cholinergic function and are used to treat memory deficits in humans (Rudakewich et al., 2001). Ginsenosides increased levels of dopamine and norepinephrine in the cerebral cortex (Itoh et al., 1989) and have beneficial effects on attention, cognitive processing, sensorimotor function and auditory reaction time in healthy subjects (D'angelo et al., 1986).

\section{Materials and Method}

Animals

Male Wistar rats (weighing 120-150g), 6-weeks-old, were obtained from the animal farm of the Egyptian Holding Company for Biological
Products and Vaccines, Egypt. Upon arrival. The animals were allowed to acclimatize for 1 week before starting the experiment. The animals were kept under standard conditions and were allowed free access to a standard requirement diet and water ad libitum. The animals were kept under a controlled lighting condition (light:dark, 13h-11h). The animals' treatment protocol was approved by the Animal Care Committee of the National Center for Radiation Research and Technology (NCRRT), Atomic Energy Authority, Cairo, Egypt.

\section{Irradiation}

Whole-body gamma irradiation was performed at the National Centre for Radiation Research and Technology (NCRRT), Atomic Energy Authority, Cairo, Egypt, using (137 cesium) Gamma Cell-40 biological irradiator. The animals were irradiated at an acute single dose level of 6 Gy delivered at a dose rate of $0.49 \mathrm{~Gy} / \mathrm{min}$.

\section{Chemicals}

Aqueous Ginseng extract $(0.933 \mathrm{~g} / 100 \mathrm{ml}$ as syrup) was purchased from PharcoPharmaceuticals, Alexandria, Egypt. It was administrated orally to rats at a dose of $100 \mathrm{mg} /$ $\mathrm{kg}$ body weight for 7 consecutive days (Sloley et al., 1999).

\section{Experimental design}

The male albino rats were divided into four groups, 6 rats in each group, and treated in parallel. In the control group (C), rats were administered saline orally $(1 \mathrm{ml})$ for 7 consecutive days. The second group (G) was administered ginseng (100mg/kg body weight) orally for 7 consecutive days. Rats in the third group $(\mathrm{R})$ received saline orally for 7 consecutive days before $\gamma$-irradiation (6Gy). The fourth group $(\mathrm{G}+\mathrm{R})$ received ginseng $(100 \mathrm{mg} / \mathrm{kg})$ orally for 7 consecutive days, one hour later rats were exposed $\gamma$-irradiation (6Gy).

\section{Biochemical assays}

Twenty-four hours after irradiation, animals were sacrificed, the blood samples were collected and serum obtained by centrifugation (Sorvall TC centrifuge, Hamburg, Germany) at 750xg at room temperature for $10 \mathrm{~min}$.

\section{Determination of serum nitric oxide and $A D M A$}

Serum nitric oxide (NO) content was measured as total nitrates/nitrites, and this assay determines total NO based on the chemical reduction of 
nitrate to nitrite (Griess reaction) according to the method of Miranda et al. (2001). Asymmetric dimethyl arginine (ADMA) was estimated using a standard enzyme linked immunosorbent assay (ELISA) method according to the manufacturer's instructions (Immundiagnostik AG, Bensheim/ Germany).

Determination of oxidative stress biomarkers

Brain was quickly excised, washed with saline, blotted with a piece of filter paper and divided into two parts. The first part was homogenized in $5-10 \mathrm{ml}$ cold $50 \mathrm{mM}$ sodium phosphate buffer $\left(100 \mathrm{mM} \quad \mathrm{Na}_{2} \mathrm{HPO}_{4} / \mathrm{NaH}_{2} \mathrm{PO}_{4}\right) \quad(\mathrm{pH} \quad 7.4)$ and centrifuged at $2795 \mathrm{xg}$ for $30 \mathrm{~min}$. The resulting supernatant was transferred into Eppendorf tubes and preserved at $-80^{\circ} \mathrm{C}$ until used for biochemical assays. The reduced glutathione (GSH) content was determined photometrically at $412 \mathrm{~nm}$ using 5,5-dithiobis-2-nitrobenzoic acid and the results were expressed as $\mu \mathrm{mol} / \mathrm{g}$ tissue using the methods of Beutler et al. (1963). The lipid peroxidation product, malondialdehyde (MDA) was measured by thiobarbituric acid assay, which is based on the reaction of MDA with thiobarbituric acid reactive substances (TBARS), a pink-colored complex exhibiting a maximum absorption at $532 \mathrm{~nm}$ and the results were expressed as $\mathrm{nmol} / \mathrm{g}$ tissue using the method of Yoshioka et al. (1979). Superoxide dismutase (SOD) activities were determined in homogenate according to the methods of Minami \& Yoshikawa (1979) and the results were expressed as $\mu \mathrm{g} / \mathrm{g}$ tissue. Catalase (CAT) activity was assayed by the method of Sinha (1972) and the results were expressed as $\mu \mathrm{mol} / \mathrm{g}$ tissue.

\section{Determination of neurotransmitters}

The second part of brain was weighed, and $10 \%(\mathrm{w} / \mathrm{v})$ tissue homogenates were prepared in $75 \%$ aqueous HPLC grade methanol. The homogenates were centrifuged at $1006 \mathrm{xg}$ for $10 \mathrm{~min}$ and the supernatants were separated and used for the neurotransmitter determination. The catecholamines; dopamine, norepinephrine and serotonin were determined according to the method of Pagel et al. (2000) and the concentration expressed in $\mu \mathrm{g} / \mathrm{g}$ tissue. Acetylcholine (Ach) was measured according to the method of Oswald et al. (2008) based on the oxidation of free choline to betaine via the intermediate betaine aldehyde. The reaction generates products which can be measured at $570 \mathrm{~nm}$ and the concentration expressed in $\mu \mathrm{mol} / \mathrm{g}$ tissue.

\section{Histological studies}

Brain sections were kept in Bouin's fixative, dehydrated in ascending grades of alcohol, cleared with xylol, embedded and impregnated in paraffin wax, sectioned at $5 \mu \mathrm{m}$ thick sections and subjected to hematoxyline and eosin: For studying the general structure of brain using light microscopy according to Drury \& Wallington (1980).

\section{Immunohistochemistry for eNOS}

Brain sections were rehydrated and immunostained with primary antibodies against eNOS (Transduction Lab, Hercules, CA, USA; 1:500) followed by an appropriate biotinylated secondary antibody. Stains were visualized using the $\mathrm{ABC}$ kit (Vector Laboratories Inc, CA, USA; (Lee et al., 2001), then reacted with diaminobenzidine (DAB; Sigma, St. Louis, USA) as a substrate and counterstained with hematoxylin. All incubation steps were performed in a humidified chamber.

\section{Statistical analysis}

Statistical analysis was performed by one way analysis of variance (ANOVA) followed by Duncan 's Multiple Range test by using statistical package of social science (SPSS) version 15.0 for windows. $\mathrm{P}$ values $<0.05$ were considered as level of significance. Values expressed are means \pm standard error of means (SEM).

\section{Results}

Figure 1 shows the effects of ginseng, gammairradiation and their combination on the levels of GSH and MDA, the activity of SOD and CAT in tissue. Gamma-irradiation exposure resulted in a significant decrease in GSH content, SOD and CAT activities and a significant increase in MDA level respectively, as compared to the control group. Treatment with ginseng for 7 consecutive days prior to irradiation resulted in a significant increase in the activities of SOD and CAT and in GSH content, respectively, and a significant decrease in MDA level compared to the irradiated group.

Figure 2 illustrates the effects of ginseng, gamma-irradiation and their combination on the levels of serotonin (5-HT), dopamine (DA), norepinephrine (NE) and acetylcholine (Ach) in brain tissues. Gamma-irradiation exposure resulted in a significant decrease in serotonin (5- 
HT), dopamine (DA), norepinephrine (NE) and acetylcholine (Ach) respectively, as compared to the control group. Treatment with ginseng for 7 consecutive days prior to irradiation resulted in a significant increase in the-concentrations of serotonin(5-HT), dopamine (DA), norepinephrine (NE) and acetylcholine (Ach) respectively, as compared with the irradiated group.
Figure 3 shows the effects of ginseng, irradiation and their combination on serum NO and ADMA. Gamma-irradiation resulted in a significant increase in the level of serum ADMA and significant decrease in serum (NO) level compared to control. Administration of ginseng for 7 consecutive days before irradiation significantly reduced the level of serum ADMA and the increase in serum (NO) level compared to the irradiated group.
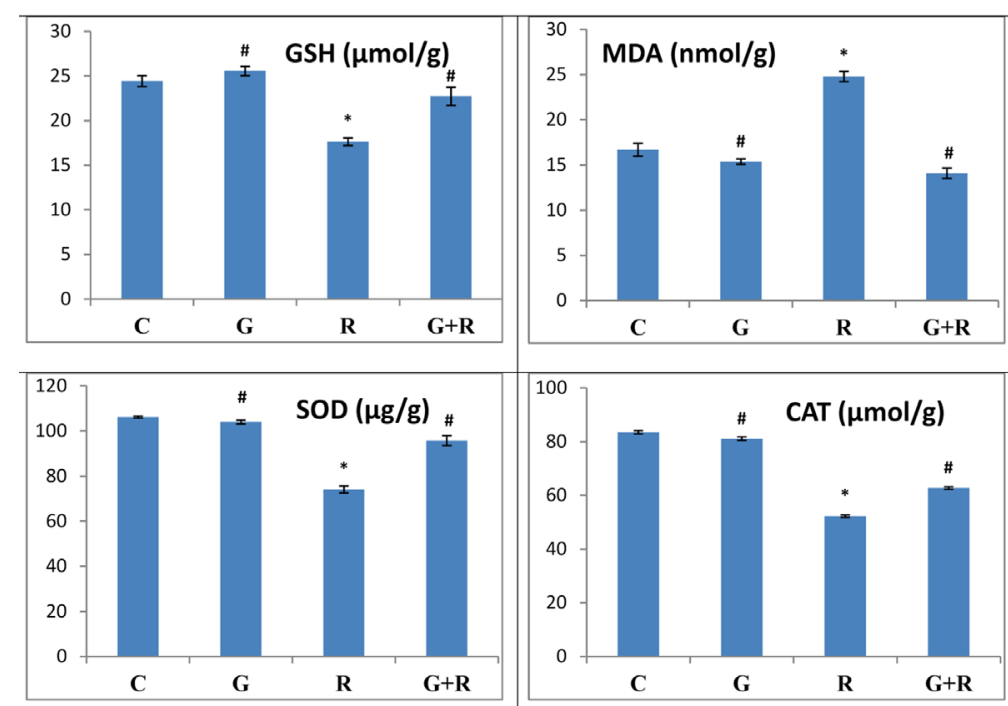

Fig. 1. Effect of Ginseng (G), irradiation $(R, 6 G y)$ and their combination $(G+R)$ on the levels of malondialdehyde (MDA) and glutathione (GSH), and superoxide dismutase (SOD) and catalase (CAT) activities in rat brain tissue (Data are presented as mean \pm SEM, $n=6 .{ }^{*}$ and ${ }^{*}$ indicate significant changes from control and $\mathrm{R}$ respectively at $\mathbf{P}<\mathbf{0 . 0 5}$ using ANOVA followed by Duncan as a post ANOVA test).
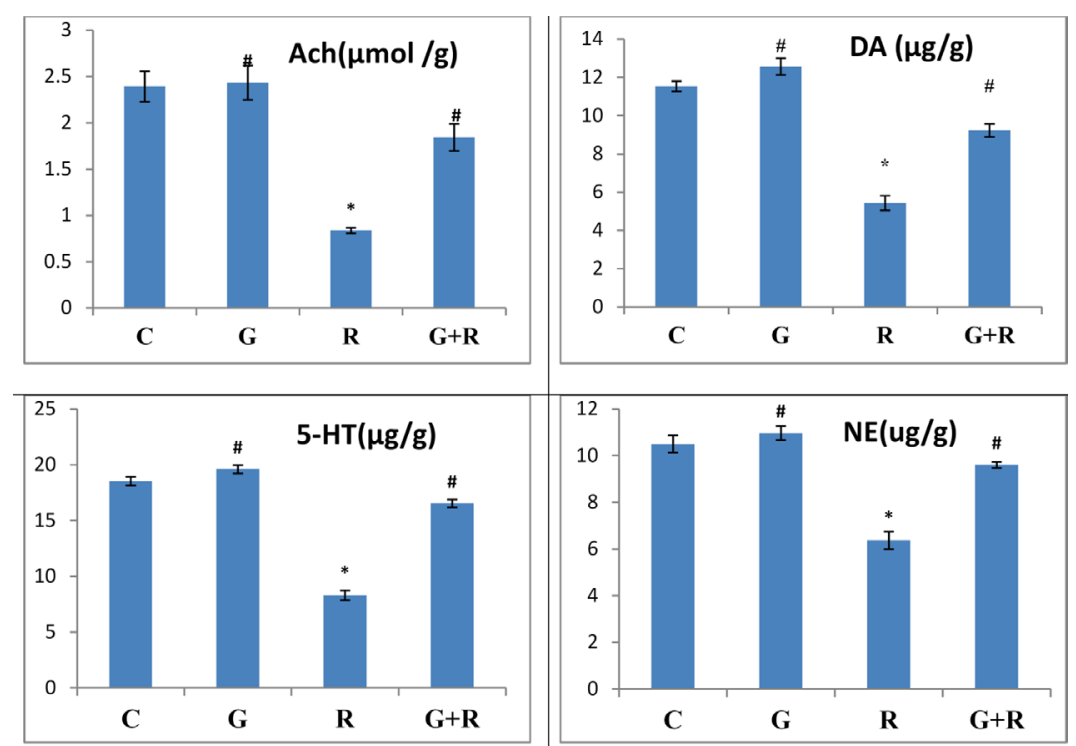

Fig. 2. Effect of Ginseng (G), irradiation (R, 6Gy) and their combination (G+R) on the concentration of the neurotransmitters serotonin (5-HT), dopamine (DA), norepinephrine (NE) and acetylcholine (Ach) in rat brain tissue (Data are presented as mean $\pm \operatorname{SEM}, n=6 .{ }^{*}$ and ${ }^{*}$ indicate significant changes from control and $R$ respectively at $\mathrm{P}<0.05$ using ANOVA followed by Duncan as a post ANOVA test). 

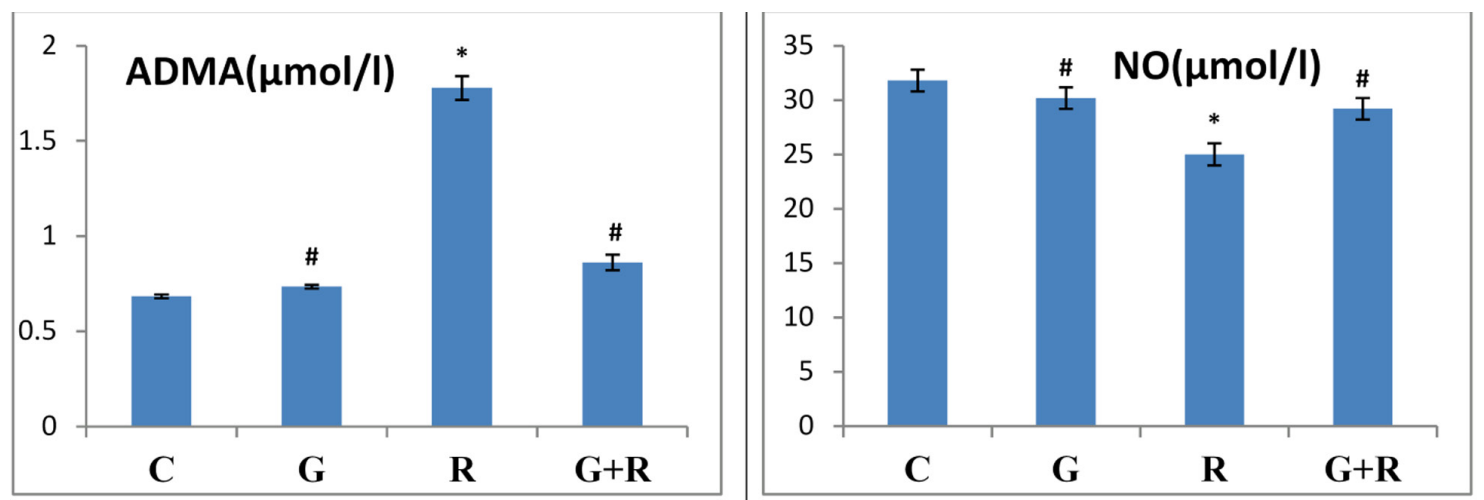

Fig. 3. Effect of Ginseng (G), irradiation (R, $6 G y)$ and their combination $(G+R)$ on serum asymmetric dimethyl arginine (ADMA) and nitric oxide (NO) in rats (Data are presented as mean $\pm S E M, n=6 .{ }^{*}$ and ${ }^{\#}$ indicate significant changes from control and $\mathrm{R}$ respectively at $\mathrm{P}<0.05$ using ANOVA followed by Duncan as a post ANOVA test).

\section{Histopathological examination of brain}

Microscopically, the cerebral cortex of rats from groups $\mathrm{C}$ and $\mathrm{G}$ revealed no histopathological changes (Fig. 4 a \& b). In contrast, brain of rats from group $\mathrm{R}$ revealed necrosis, pyknosis and atrophy of neurons (Fig. 4 c). Improved histopathological picture was observed in the brain of rats from group $\mathrm{G}+\mathrm{R}$, as most examined sections revealed no histopathological changes except for necrosis of sporadic neurons (Fig. 4 d).

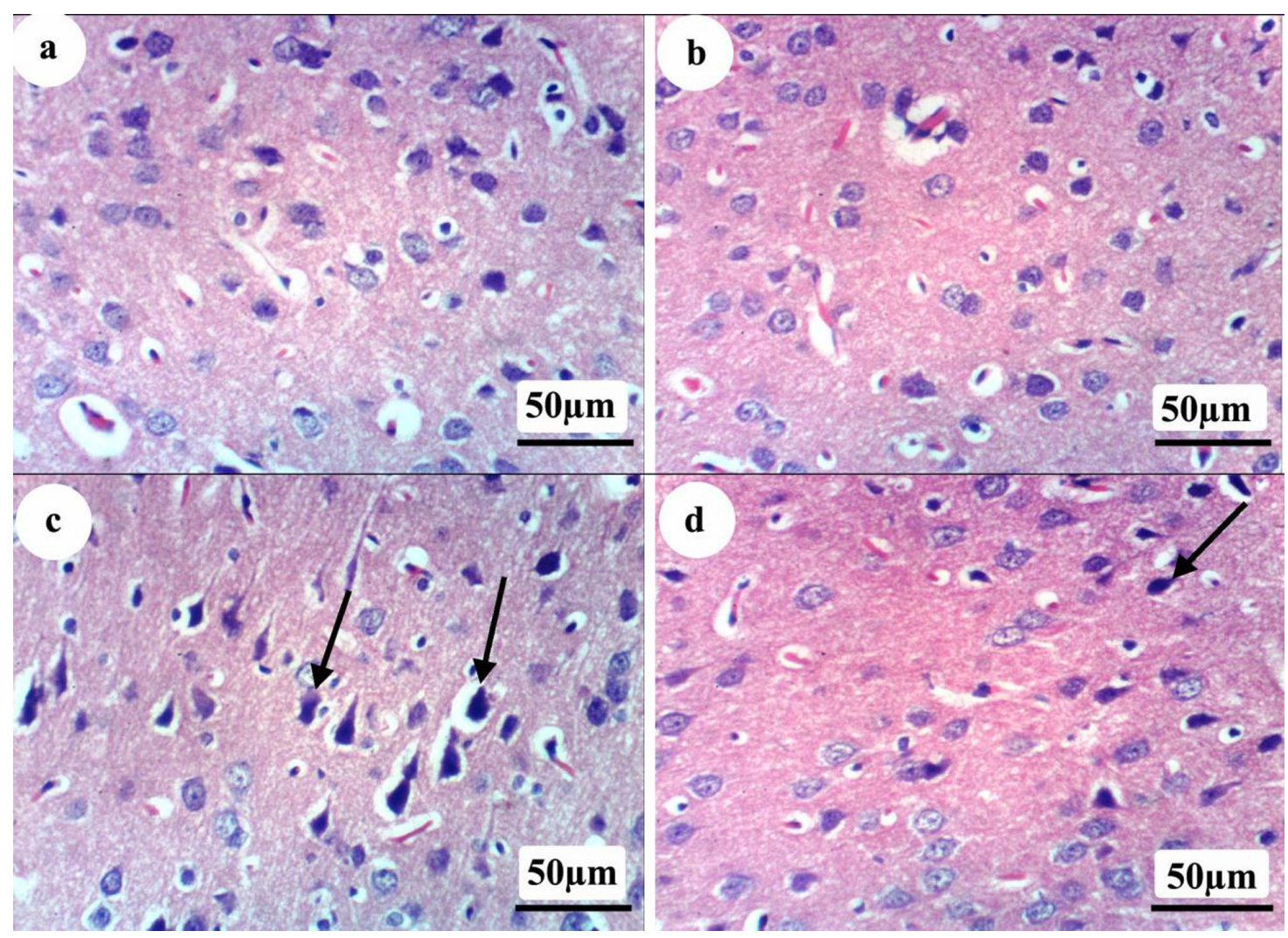

Fig. 4. Histological examination of the cerebral cortex of rats, (a) Control group showed normal architecture (H \& E X 400), (b) G group showed no histopathological changes (H \& E X 400), (c) R group showed necrosis, pyknosis and atrophy of neurons (arrow) (H \& E X 400) and (d) G+R group showed necrosis of sporadic neurons (arrow) (H \& E X 400) 
Immunohistochemical staining of brain sections

The effect of ginseng on the cerebral cortex infarction following irradiation-induced brain damage was examined by immunohistochemical analysis of e-NOS expression in the brain tissue (Fig. 5). Cerebral tissue of the normal control group (C) and $\mathrm{G}$ showed no expression of e-NOS (negative immunohistochemical reaction) indicating normal biological processes (Fig. 5 a $\&$ b). In contrast, tissue of the irradiated group showed a strong positive expression of e-NOS (immunopositivity indicated by brown color) indicating abnormal neurons and cerebral damage (Fig. 5 c). While, groups that administered ginseng for 7 consecutive days before irradiation showed a weak positive expression of e-NOS (immunopositivity indicated by brown color) indicating reduced cerebral damage comparable to irradiated group (Fig. 5 c) and (Fig. 5 d), respectively.

\section{Discussion}

The steady increasing use of radiation technologies in medicine, industry, agriculture and scientific research has been paralleled with the increase of its potential risk factors. Furthermore, advanced research in the activity of the radio-protective plants and herbal extracts against ionizing radiation disorders, free radicals and oxidative stress has achieved more interest in the last decades (Jagetia, 2007).

Experimental evidence has considered the brain a radiosensitive organ because of its high $\mathrm{O}_{2}$ utilization rate, its high content of polyunsaturated fatty acids, which are prone to lipid peroxidation, and its high content of iron which through the Fenton reactions increases the formation of free radicals (Halliwell, 2001). In addition, relative to other organs, brain tissues are poor in antioxidants (Sherki et al., 2001).

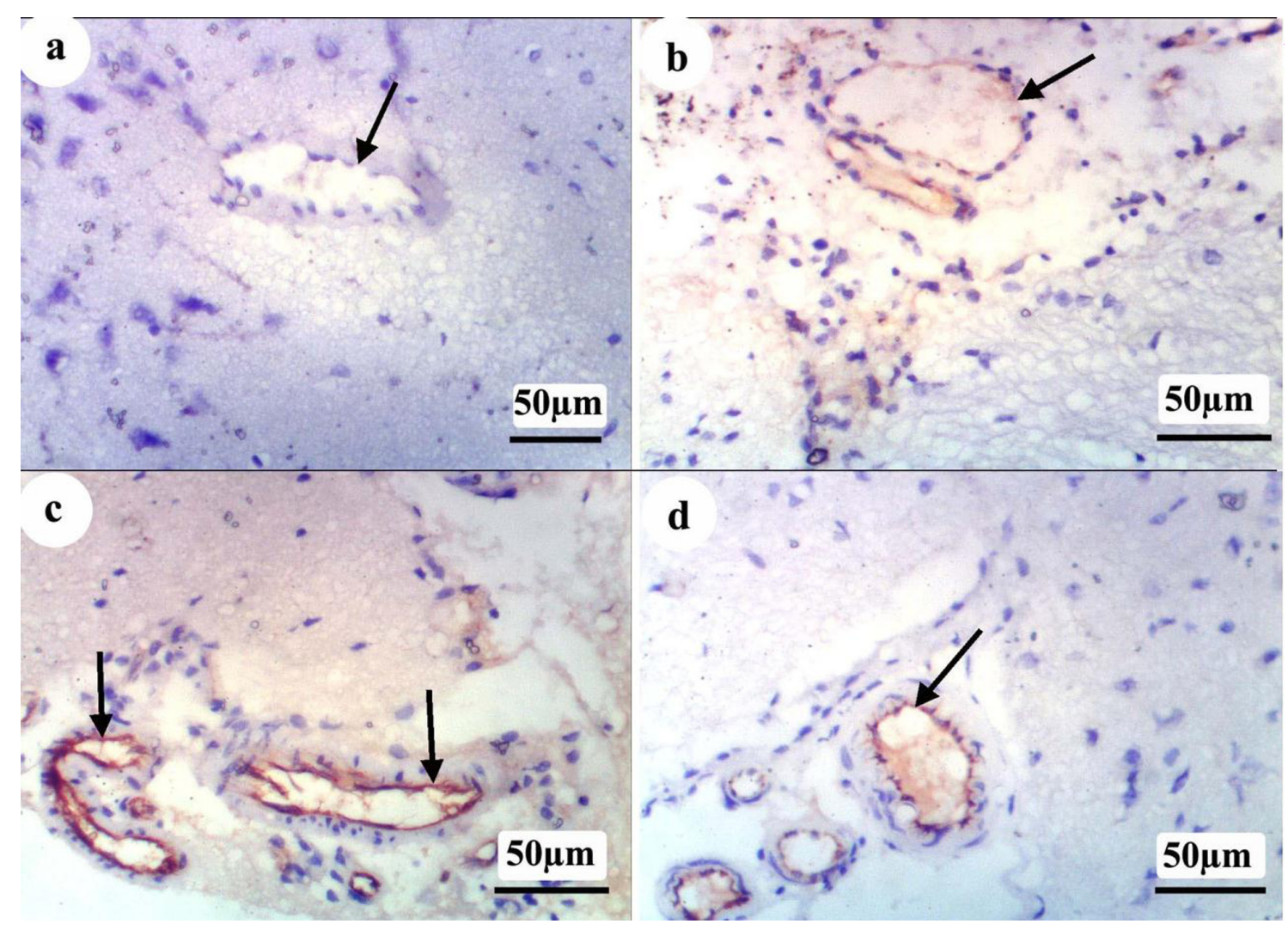

Fig. 5. Immunohistochemical staining of e-NOS in the cerebral cortex of rat, (a) Control group showed no expression of e-NOS (negative immunohistochemical reaction) (X 400), (b) G group showed no expression of e-NOS (negative immunohistochemical reaction) (X 400), (c) R group showed strong positive expression of e-NOS (immunopositivity indicated by brown color) (arrow) (X 400) and (d) G+R group showed weak positive expression of e-NOS (immunopositivity indicated by brown color) (arrow) (X 400) 
Antioxidant enzymes are influenced by oxidation status, and changes in their activity can serve as a biomarker for oxidative stress (Voss \& Siems, 2006). In the present study, whole body exposure of male albino rats to gamma irradiation (6Gy) has provoked an imbalance between oxidant and antioxidant species in the brain of rats. Significant increase in MDA level accompanied by significant decrease of SOD, CAT activities and GSH content were recorded.

The elevation of brain MDA level is probably due to the interaction of $\bullet \mathrm{OH}$ resulting as a byproduct of water radiolysis, upon exposure of rats to ionizing radiation, with the polyunsaturated fatty acids present in the phospholipids portion of cellular membranes suggests the participation of free-radical-induced oxidative cell injury in mediating the toxicity of ionizing radiation (IR) (Saada et al., 2003). Deloncle et al. (1999) reported that the neurotoxicity of IR is due to the increase in lipid peroxidation and damage of the blood-brain barrier. The increase in MDA level in the brain suggests enhanced peroxidation leading to tissue damage and failure of the antioxidant mechanisms to prevent the production of excessive free radicals. Similar results were previously reported in kidney (Ogeturk et al., 2005) and liver (Yang et al., 2008) tissues.

Lipids are the macromolecules the most susceptible to oxidative stress, which play a major role in the production of MDA (Nazam et al., 2008). The level of MDA in the homogenate of the cerebral cortex of rats was measured to evaluate the oxidative stress induced by irradiation. The results showed that treatment with Panax ginseng extract markedly reduced the MDA level in the brain tissue affected by irradiation injury indicating the efficiency of Panax ginseng in decreasing the oxidative stress of irradiation.

The presence of numerous antioxidant enzymes in the brain, including SOD and CAT, protects these tissues from oxidative damage caused by the formation of free radicals (Cui et al., 2004). SOD reacts with superoxide radicals to form $\mathrm{H}_{2} \mathrm{O}_{2}$ and CAT, which is found at very low levels in the brain, detoxifies $\mathrm{H}_{2} \mathrm{O}_{2}$ into $\mathrm{H}_{2} \mathrm{O}$. Oxidative stress reduces the activity of these enzymes. In the current study the activity of the endogenous antioxidant enzymes, SOD, and CAT, decreased significantly following irradiation. Administration of the Panax ginseng extract increased the activity of the endogenous antioxidant enzymes to the control levels. The activity of the Panax ginseng extract appears to work by restoring the altered antioxidant enzyme activity and decreasing the rate of lipid peroxidation.

The decrease in the activities of SOD and the decreased level of GSH might be due to their utilization by the enhanced production of ROS, which interacts with the enzyme molecules causing their denaturation and partial inactivation (Maurya et al., 2006 and Kregel \& Zhang, 2007). Under normal conditions, the inherent defense system, including glutathione and the antioxidant enzymes, protects against oxidative damage. GSH, a well-known antioxidant, provides major protection in oxidative injury by participating in the cellular system of defense against oxidative damage (Şener et al., 2006).

GSH is involved in several defense processes against oxidative damage. It protects cells against free radicals, peroxides and other toxic compounds (Sies, 1999). Indeed, glutathione depletion increases the sensitivity of cells to various insults and also has several metabolic effects. It is widely known that a deficiency of GSH within living organisms can lead to tissue disorder and injury (Limón-Pacheco et al., 2007).

Administration of ginseng markedly elevated the levels of antioxidant enzymes indicating the antioxidant potential of the ginseng. This might be due to metabolized ginsenosides, which protect the outer membrane of mammalian cells (Block \& Mead, 2003 and Lee et al., 2009) scavenge free radicals, restore the GSH level and inhibit NO production (Zhu et al., 2009 and Zhang et al., 2014). Panax ginseng extract has been shown to inhibit lipid peroxidation through transition metal chelation and scavenging of hydroxyl and superoxide radicals (Kitts et al., 2000). The antioxidant action of this Panax ginseng extract is due to its components, the flavonol glycosides, which are known for scavenging superoxide and then preventing anion and hydroxyl radical lipid peroxidation in the membranes (Attele et al., 1999). It has been also reported that Panax ginseng administration increased the activity of the antioxidant enzymes SOD, CAT and GSH content in rats (Sun, 2011 and Sena et al., 2012).

In the present study, whole body exposure of male albino rats to gamma irradiation (6Gy) 
induced a significant decrease of monoamine levels in brain that could be attributed to radiation-induced oxidative stress and oxidation of monoamines. Oxidative stress and inflammation cause deficiencies of many of the major neurotransmitters; serotonin, norepinephrine, acetylcholine and also deplete dopamine (Crockett et al., 2008). However, the decrease of monoamine levels may be due to alterations in the dopaminergic system (Delgado et al., 2000) or might be attributed to decreased synthesis resulting from radiation-induced damage to the ileal mucosa and reduction in net ilea absorption, where a decrease in the absorption of tryptophan would reduce the synthesis of serotonin, while a decrease in absorption of L-tyrosine may diminish the production of DA, NE and EPI (Martin et al., 2001). Oxidative stress significantly induced an alteration in electrolyte concentrations that probably reflects a significant decrease in all studied neurotransmitter levels (Bardov et al., 1990). Furthermore, significant alterations of brain neurotransmitters (DA, 5-HT, $\mathrm{NE}$ and $\mathrm{ACh}$ ) in irradiated rats may be attributed to the increased rate of formation of $\mathrm{O}_{2} \cdot-$ and $\mathrm{H}_{2} \mathrm{O}_{2}$ in the hippocampus and may be responsible for exerting neurodegenerative diseases and Lewy bodies aggregations (Burke et al., 2004).

The active ingredients of ginseng extracts initiate multiple actions in the brain tissue areas interacting with the neuronal circuit through the effect on neurotransmitter levels to maintain homeostasis on the neuronal function and may add to its beneficial effects on the neurodegenerative diseases especially on the memory dysfunction. Sun et al. (2013) demonstrated that Panax ginseng treatment at $100 \mathrm{mg} / \mathrm{kg}$ per day attenuated the decrease in the levels of serotonin, dopamine, norepinephrine and acetylcholine in the prefrontal cortex of mice exposed to chronic mild stress (CMS). They showed that chronic treatment with Panax ginseng $(100 \mathrm{mg} / \mathrm{kg})$ reversed the reduction of ACh levels in the prefrontal cortex, which implied that it might improve cognition by modulating the cholinergic system.

In the present study, the $\gamma$-irradiated rats showed a significant increase in serum ADMA concomitantly with a significant decrease in NO level. This effect is probably mediated by oxidative stress (Maas et al., 2007). In agreement with our results, previous studies of Ueda et al. (2007) and Wilcox (2012) have reported elevated ADMA levels and decreased NO levels in states of cardiovascular diseases and chronic kidney disease in human and rat and also in the response of endothelial cells to ionizing radiation (Lanza et al., 2007). Elevated levels of ADMA inhibit NO synthesis and therefore impair endothelial function (Sibal et al., 2010). Reduction of $\mathrm{NO}(\mathrm{x})$ levels might be due to both decreased production and increased consumption, with possible endothelial dysfunction and vascular impairment (Soloviev et al., 2003). Consistent with previous studies (Kim \& Lee, 2010 and Pan et al., 2012) ADMA increase and its association with stroke outcome might represent not only a marker, but also a mediator for brain injury after acute stroke. One effect of ADMA might be the restriction of cerebral blood flow (CBF). ADMA could play an important role on cerebrovascular compliance and $\mathrm{CBF}$ in resting conditions and after the acute stroke by inhibition of NOS, since NO is the most important endogenous vasodilator for regulation of CBF (Iadecola et al., 1994). A cell culture study showed that ADMA inhibited NO production from neuronal nitric oxide synthase (nNOS) and protected neurons from overexpressed NO mediated injury. Therefore, ADMA might have a protective effect on the central nervous system (CNS) (Cardounel \& Zweier, 2002).

The present study showed that the endothelial $\mathrm{NO}(\mathrm{x})$ and ADMA levels were ameliorated by the administration of ginseng. Kim et al. (2009) and Shah et al. (2005) reported that administration of ginseng to rats offered marked protection against ischemia/reperfusion-induced brain damage, as evidenced by a significant reversal of enzymatic alterations. Pan et al. (2012) observed that, ginseng reduced ROS production and increased NO levels, thus ameliorating endothelial dysfunction. Panax ginseng was reported to improve the release of inflammatory mediators such as NOS (Huang et al., 2016) and thus enhance the release of nitric oxide (NO) from endothelial cells of the rat aorta and kidney. It was mentioned also to protect the heart from injury via up-regulation of endothelial NO synthase (eNOS) expression (Hare \& Stamler, 2005 and Wu et al., 2011), resulting in $\mathrm{Ca}^{2+}$ channel inhibition, activation of cardiac potassium channels and protection against ischemia-reperfusion injury (Wang et al., 2008 and Szelid et al., 2010). The protection afforded by ginseng was attributed to its role in reducing oxidative stress, Kim \& Lee (2010) suggesting that some of the observed effects of ginseng are possibly mediated through its antioxidant property. 
In accordance with the previous biochemical profile, the histopathological and immunehistochemical examinations of brain sections obtained from the irradiation group $(\mathrm{R})$ revealed necrosis, pyknosis and atrophy of neurons (Fig. $4 \& 5 \mathrm{c}$ ). The results corroborate the previous findings of Hornsey et al. (1981) and Mansour et al. (2011). Brain sections from the ginseng group showed preserved normal architecture of the brain (cerebral cortex). The administration of ginseng to the irradiated rats, as shown in $\mathrm{G}+\mathrm{R}$ group resulted in the amelioration of changes elicited by irradiation, and suggested that ginseng is neuroprotective. The results are in line with the observations of Jiang \& Qian (1995) and Wen et al. (1995) who attributed the protective effects of ginseng to the antioxidant role of ginsenosides on survival of neurons, which may be mediated through improving the energy metabolism and preserving the structural integrity of neurons in the prevention of delayed neuronal death. In vivo or in vitro studies previously discussed the ginsenosides rescue possibility on neuronal cells by increasing cell survival, extending neurite growth and rescuing neurons from death (Radad et al., 2006 and Rausch et al., 2006). Moreover, $\mathrm{Hu}$ et al. (2008) recorded that ginsenoside significantly reduced the scores for neurological deficits and brain edema, improved the activities of superoxide dismutase (SOD), lowered the content of malondialdehyde (MDA) and reduced the cerebral infraction area.

\section{Conclusion}

Panax ginseng has shown a significant radioprotective effect against ionizing radiationinduced oxidative stress and brain injury may be due to scavenging the free radicals and by increasing the antioxidant status. Thus, supplementation with Panax ginseng may help in safer application of irradiation technology in medicine as well as in many other aspects of nowadays life.

Acknowledgement: The authors acknowledge Prof. Dr. Kawkab Abdel-Aziz, Pathology Department, Faculty of Veterinary Medicine, Cairo University for accomplishing the examination of brain sections in the current study.

\section{Authors' Contributions}

All authors participated equally in this work.

\section{Declaration of Interest}

The authors report no declaration of interest. The authors are solely responsible for the content and writing of the paper.

\section{References}

Attele, A.S., Wu, J.A. and Yuan, C.S. (1999) Ginseng pharmacology: multiple constituents and multiple actions. Biochem. Pharmacol. 58, 1685-1693.

Bajaj, J.S., Ahluwalia, V., Wade, J.B., Sanyal, A.J., White, M.B., Noble, N.A., Monteith, P., Fuchs, M., Sterling, R.K. and Luketic, V. (2013) Asymmetric dimethylarginine is strongly associated with cognitive dysfunction and brain MR spectroscopic abnormalities in cirrhosis. J. Hepatol. 58, 38-44.

Bardov, V., Shmuter, G., Suchkov, B., Stepanenko, G. and Omel'chuk, S. (1990) Effect of ultraviolet irradiation on calcium, sodium and potassium levels in albino rats. Gig. Sanit. 5, 74-76.

Beutler, E., Duron, O. and Kelly, B.M. (1963) Improved method for determination of blood glutathione. $J$. Lab. Clin. Med., 61, 882-888.

Block, K.I. and Mead, M.N. (2003) Immune system effects of echinacea, ginseng, and astragalus: A review. Integr. Cancer Ther. 2, 247-267.

Burke, W.J., Li, S.W., Chung, H.D., Ruggiero, D.A., Kristal, B.S., Johnson, E.M., Lampe, P., Kumar, V.B., Franko, M. and Williams, E.A. (2004) Neurotoxicity of MAO metabolites of catecholamine neurotransmitters: role in neurodegenerative diseases. Neurotoxicology, 25, 101-115.

Cardounel, A.J. and Zweier, J.L. (2002) Endogenous methylarginines regulate neuronal nitric-oxide synthase and prevent excitotoxic injury. J. Biol. Chem. 277, 33995-34002.

Cheng Y., Shen, L.-H. and Zhang, J.-T. (2005) Antiamnestic and anti-aging effects of ginsenoside $\mathrm{Rg} 1$ and Rb1 and its mechanism of action. Acta Pharmacologica Sinica, 26(2), 143-149.

Crockett, M.J., Clark, L., Tabibnia, G., Lieberman, M.D. and Robbins, T.W. (2008) Serotonin modulates behavioral reactions to unfairness. Science, 320, 1739-1739. 
Cui, K., Luo, X., Xu, K. and Murthy, M.V. (2004) Role of oxidative stress in neurodegeneration: Recent developments in assay methods for oxidative stress and nutraceutical antioxidants. Prog. Neuropsychopharmacol. Biol. Psychiatry, 28, 771-799.

D’angelo, L., Grimaldi, R., Caravaggi, M., Marcoli, M., Perucca, E., Lecchini, S., Frigo, G. and Crema, A. (1986) A double-blind, placebo-controlled clinical study on the effect of a standardized ginseng extract on psychomotor performance in healthy volunteers. J. Ethnopharmacol. 16, 15-22.

Delgado, M.R., Nystrom, L.E., Fissell, C., Noll, D. and Fiez, J.A. (2000) Tracking the hemodynamic responses to reward and punishment in the striatum. J. Neurophysiol. 84, 3072-3077.

Deloncle, R., Huguet, F., Babin, P., Fernandez, B., Quellard, N. and Guillard, O. (1999) Chronic administration of aluminium L-glutamate in young mature rats: effects on iron levels and lipid peroxidation in selected brain areas. Toxicol. Lett. 104, 65-73.

Drury, R.A. B. and Wallington, E.A. (1980) "Carleton's Histological Technique". Oxford University Press, USA.

Halliwell, B. (2001) Role of free radicals in the neurodegenerative diseases. Drugs Aging. 18, 685-716.

Hare, J.M. and Stamler, J.S. (2005) NO/redox disequilibrium in the failing heart and cardiovascular system. J. Clin. Invest. 115, 509.

Hornsey, S., Morris, C.C. and Myers, R. (1981) The relationship between fractionation and total dose for $\mathrm{X}$ ray induced brain damage. International Journal of Radiation Oncology* Biology* Physics, 7, 393-396.

Hu, Y., Chen, H. and Zang, L. (2008) Protective effects ofginsenoside $\mathrm{Rb} 3$ on focal cerebral ischemic injury in rats. Journal of Guangdong College of Pharmacy, 24, 590-594.

Huang, Y., Cai, T., Xia, X., Cai, Y. and Wu, X.Y. (2016) Research advances in the intervention of inflammation and cancer by active ingredients of traditional Chinese medicine. J. Pharm. Pharm. Sci. 19, 114-126.
Iadecola, C., Pelligrino, D.A., Moskowitz, M.A. and Lassen, N.A. (1994) Nitric oxide synthase inhibition and cerebrovascular regulation. J. Cereb. Blood Flow Metab. 14, 175-192.

Itoh, T., Zang, Y.F., Murai, S. and Saito, H. (1989) Effects of Panax ginseng root on the vertical and horizontal motor activities and on brain monoamine-related substances in mice. Planta Med. 55, 429-433.

Jagetia, G.C. (2007) Radioprotective potential of plants and herbs against the effects of ionizing radiation. J. Clin. Biochem. Nutr. 40, 74-81.

Jia, C., Roman, C. and Hegg, C.C. (2010) Nickel sulfate induces location-dependent atrophy of mouse olfactory epithelium: protective and proliferative role of purinergic receptor activation. Toxicol. Sci. 115, 547-556.

Jiang, K. and Qian, Z. (1995) Effects of Panax notoginseng saponins on posthypoxic cell damage of neurons in vitro. Zhongguo yao li xue bao $=$ Acta Pharmacologica Sinica, 16, 399-402.

Jung, C.-H., Seog, H.-M., Choi, I.-W., Choi, H.-D. and Cho, H.-Y. (2005) Effects of wild ginseng (Panax ginseng CA Meyer) leaves on lipid peroxidation levels and antioxidant enzyme activities in streptozotocin diabetic rats. J. Ethnopharmacol. 98, 245-250.

Kim, T.-H. and Lee, S.-M. (2010) The effects of ginseng total saponin, panaxadiol and panaxatriol on ischemia/reperfusion injury in isolated rat heart. Food Chem. Toxicol. 48, 1516-1520.

Kim, Y.O., Kim, H.-J., Kim, G.S., Park, H.G., Lim, S.J., Seong, N.S., Ham, Y.W., Lee, S.D., Jang, K.H. and Jung, K.H. (2009) Panax ginseng protects against global ischemia injury in rat hippocampus. J. Med. Food, 12, 71-76.

Kitts, D.D., Wijewickreme, A.N. and Hu, C. (2000) Antioxidant properties of a North American ginseng extract. Mol. Cell. Biochem., 203, 1-10.

Kregel, K.C. and Zhang, H.J. (2007) An integrated view of oxidative stress in aging: basic mechanisms, functional effects, and pathological considerations. American Journal of Physiology-Regulatory, Integrative and Comparative Physiology, 292, R18-R36. 
Langer, D.A. and Shah, V.H. (2005) A gas, an amino acid, and an imposter: The story of nitric oxide, 1-arginine, and ADMA in portal hypertension. Hepatology, 42, 1255-1257.

Lanza, V., Fadda, P., Iannone, C. and Negri, R. (2007) Low-dose ionizing radiation stimulates transcription and production of endothelin by human vein endothelial cells. Radiat. Res. 168, 193-198.

Lee, J.E., Yenari, M.A., Sun, G.H., Xu, L., Emond, M.R., Cheng, D., Steinberg, G.K. and Giffard, R.G. (2001) Differential neuroprotection from human heat shock protein 70 overexpression in in vitro and in vivo models of ischemia and ischemia-like conditions. Exp. Neurol. 170, 129-139.

Lee, S.Y., Kim, G.T., Roh, S.H., Song, J.-S., Kim, H.J., Hong, S.-S., Kwon, S.W. and Park, J.H. (2009) Proteomic analysis of the anti-cancer effect of 20S-ginsenoside Rg3 in human colon cancer cell lines. Biosci. Biotechnol. Biochem. 73, 811-816.

Limón-Pacheco, J.H., Hernández, N.A., Fanjul-Moles, M.L. and Gonsebatt, M.E. (2007) Glutathione depletion activates mitogen-activated protein kinase (MAPK) pathways that display organspecific responses and brain protection in mice. Free Radic. Biol. Med. 43, 1335-1347.

Liu, Z.-J., Zhao, M., Zhang, Y., Xue, J.-F. and Chen, N.-H. (2010) Ginsenoside Rg1 promotes glutamate release via a calcium/calmodulin-dependent protein kinase II-dependent signaling pathway. Brain Res. 1333, 1-8.

Loganovsky, K.N. and Yuryev, K.L. (2004) EEG patterns in persons exposed to ionizing radiation as a result of the Chernobyl accident. Part 2: quantitative EEG analysis in patients who had acute radiation sickness. The Journal of Neuropsychiatry and Clinical Neurosciences, 16, 70-82.

Maas, R., Schulze, F., Baumert, J., Löwel, H., Hamraz, K., Schwedhelm, E., Koenig, W. and Böger, R.H. (2007) Asymmetric dimethylarginine, smoking, and risk of coronary heart disease in apparently healthy men: Prospective analysis from the population-based Monitoring of Trends and Determinants in Cardiovascular Disease/ Kooperative Gesundheitsforschung in der Region Augsburg study and experimental data. Clin. Chem. 53, 693-701.
Mansour, S., Hanafi, N. and Noaman, E. (2011) Aluminium and gamma irradiation induced oxidative damage in brain tissue of male ratsprotective role of ferulic acid. Journal of Radiation Research and Applied Sciences, 4, 1163-1188.

Martin, A.O., Mathieu, M.-N., Chevillard, C. and Guérineau, N.C. (2001) Gap junctions mediate electrical signaling and ensuing cytosolic $\mathrm{Ca}^{2+}$ increases between chromaffin cells in adrenal slices: A role in catecholamine release. J. Neurosci. 21, 5397-5405.

Maurya, D.K., Devasagayam, T. and Nair, C.K.K. (2006) Some novel approaches for radioprotection and the beneficial effect of natural products. Indian J Exp Biol. 44(2), 93-114.

Minami, M. and Yoshikawa, H. (1979) A simplified assay method of superoxide dismutase activity for clinical use. Clin. Chim. Acta, 92, 337-342.

Miranda, K.M., Espey, M.G. and Wink, D.A. (2001) A rapid, simple spectrophotometric method for simultaneous detection of nitrate and nitrite. Nitric Oxide, 5, 62-71.

Nazam, M., Bhandari, U., Islam, F. and Tripathi, C. (2008) Evaluation of antioxidant and neuroprotective effect of ethanolic extract of Embelia ribes Burm in focal cerebral ischemia/ reperfusion-induced oxidative stress in rats. Fundam. Clin. Pharmacol. 22, 305-314.

Ogeturk, M., Kus, I., Colakoglu, N., Zararsiz, I., Ilhan, N. and Sarsilmaz, M. (2005) Caffeic acid phenethyl ester protects kidneys against carbon tetrachloride toxicity in rats. J. Ethnopharmacol. 97, 273-280.

Oswald, C., Smits, S.H., Höing, M., Sohn-Bösser, L., Dupont, L., Le Rudulier, D., Schmitt, L. and Bremer, E. (2008) Crystal structures of the choline/ acetylcholine substrate-binding protein ChoX from Sinorhizobium meliloti in the liganded and unliganded-closed states. J. Biol. Chem. 283, 32848-32859.

Pagel, P., Blome, J. and Wolf, H.U. (2000) Highperformance liquid chromatographic separation and measurement of various biogenic compounds possibly involved in the pathomechanism of Parkinson's disease. Journal of Chromatography B: Biomedical Sciences and Applications, 746, 297-304 
Pan, C., Huo, Y., An, X., Singh, G., Chen, M., Yang, Z., $\mathrm{Pu}, \mathrm{J}$. and Li, J. (2012) Panax notoginseng and its components decreased hypertension via stimulation of endothelial-dependent vessel dilatation. Vascul. Pharmacol. 56, 150-158.

Radad, K., Gille, G., Liu, L. and Rausch, W.-D. (2006) Use of ginseng in medicine with emphasis on neurodegenerative disorders. J. Pharmacol. Sci. 100, 175-186.

Rausch, W., Liu, S., Gille, G. and Radad, K. ( 2006) Neuroprotective effects of ginsenosides. Acta Neurobiol. Exp. (Wars.), 66, 369-375.

Rudakewich, M., Ba, F. and Benishin, C.G. (2001) Neurotrophic and neuroprotective actions of ginsenosides Rb1 and Rg1. Planta Med. 67, 533537.

Saada, H., Ussama, Z. and Mahdy, A. (2003) Effectiveness of Aloe vera on the antioxidant status of different tissues in irradiated rats. Die PharmazieAn International Journal of Pharmaceutical Sciences, 58, 929-931.

Selley, M. (2003) Increased concentrations of homocysteine and asymmetric dimethylarginine and decreased concentrations of nitric oxide in the plasma of patients with Alzheimer's disease. Neurobiol. Aging, 24, 903-907.

Sena, S., Chen, S., Feng, B., Wu, Y., Lui, E. and Chakrabarti, S. (2012) Preventive effects of North American ginseng (Panax quinquefolium) on diabetic nephropathy. Phytomedicine, 19, 494-505.

Şener, G., Kabasakal, L., Atasoy, B.M., Erzik, C., Velioğlu-Öğünç, A., Çetinel, Ş., Gedik, N. and Yeğen, B.Ç. (2006) Ginkgo biloba extract protects against ionizing radiation-induced oxidative organ damage in rats. Pharmacol. Res. 53, 241-252.

Shah, Z.A., Gilani, R.A., Sharma, P. and Vohora, S.B. (2005) Cerebroprotective effect of Korean ginseng tea against global and focal models of ischemia in rats. J. Ethnopharmacol. 101, 299-307.

Sherki, Y., Melamed, E. and Offen, D. (2001) Oxidative stress induced-neurodegenerative diseases: The need for antioxidants that penetrate the blood brain barrier. Neuropharmacology, 40, 959-975.

Sibal, L., Agarwal, S.C., Home, P.D. and Boger, R.H.
(2010) The role of asymmetric dimethylarginine (ADMA) in endothelial dysfunction and cardiovascular disease. Curr. Cardiol. Rev. 6, 82-90.

Sies, H. (1999) Glutathione and its role in cellular functions. Free Radic. Biol. Med. 27, 916-921.

Sinha, A.K. (1972) Colorimetric assay of catalase. Anal. Biochem. 47, 389-394.

Sloley, B.D., Pang, P., Huang, B.-H., Ba, F., Li, F.L., Benishin, C.G., Greenshaw, A.J. and Shan, J.J. (1999) American ginseng extract reduces scopolamine-induced amnesia in a spatial learning task. J. Psychiatry Neurosci. 24, 442.

Soloviev, A.I., Tishkin, S.M., Parshikov, A.V., Ivanova, I.V., Goncharov, E.V. and Gurney, A.M. (2003) Mechanisms of endothelial dysfunction after ionized radiation: Selective impairment of the nitric oxide component of endothelium-dependent vasodilation. Br. J. Pharmacol. 138, 837-844.

Spitz, D.R., Azzam, E.I., Li, J.J. and Gius, D. (2004) Metabolic oxidation/reduction reactions and cellular responses to ionizing radiation: A unifying concept in stress response biology. Cancer Metastasis Rev. 23, 311-322.

Starkov, A.A., Chinopoulos, C. and Fiskum, G. (2004) Mitochondrial calcium and oxidative stress as mediators of ischemic brain injury. Cell Calcium, 36, 257-264.

Sun, J., Chen, Y., Li, M. and Ge, Z. (1998) Role of antioxidant enzymes on ionizing radiation resistance. Free Radic. Biol. Med. 24, 586-593.

Sun, X.-P., Li, S.-D., Shi, Z., Li, T.-F., Pan, R.-L., Chang, Q., Qin, C. and Liu, X.-M. (2013) Antidepressantlike effects and memory enhancement of a herbal formula in mice exposed to chronic mild stress. Neurosci. Bull. 29, 737-744.

Sun, Y. (2011) Structure and biological activities of the polysaccharides from the leaves, roots and fruits of Panax ginseng CA Meyer: An overview. Carbohydrate Polymers, 85, 490-499.

Szelid, Z., Pokreisz, P., Liu, X., Vermeersch, P., Marsboom, G., Gillijns, H., Pellens, M., Verbeken, E., Van de Werf, F. and Collen, D. (2010) Cardioselective nitric oxide synthase 3 gene transfer protects against myocardial reperfusion 
injury. Basic Res. Cardiol. 105, 169-179.

Ueda, S., Yamagishi, S.-I., Matsumoto, Y., Fukami, K. and Okuda, S. (2007) Asymmetric dimethylarginine (ADMA) is a novel emerging risk factor for cardiovascular disease and the development of renal injury in chronic kidney disease. Clin. Exp. Nephrol. 11, 115-121.

Voss, P. and Siems, W. (2006) Clinical oxidation parameters of aging. Free Radic. Res. 40, 13391349.

Wang, Z., Li, M., Wu, W.-K., Tan, H.-M. and Geng, D.-F. (2008) Ginsenoside Rb1 preconditioning protects against myocardial infarction after regional ischemia and reperfusion by activation of phosphatidylinositol-3-kinase signal transduction. Cardiovasc. Drugs Ther. 22, 443-452.

Wen, T.-C., Yoshimura, H., Matsuda, S., Lim, J.-H. and Sakanaka, M. (1995) Ginseng root prevents learning disability and neuronal loss in gerbils with 5-minute forebrain ischemia. Acta Neuropathol. 91, $15-22$.

Wenbin, H., Junlong, Z. and Naihong, C. (2015) Protein kinase-based neural signaling pathways for ginsenosides: A retrospective review. Journal of Traditional Chinese Medicine, 35(3), 349-354.

Wilcox, C.S. (2012) Asymmetric dimethylarginine and reactive oxygen species. Hypertension, 59, 375-381.

Wu, Y., Lu, X., Xiang, F.-L., Lui, E.M. and Feng, Q. (2011) North American ginseng protects the heart from ischemia and reperfusion injury via upregulation of endothelial nitric oxide synthase. Pharmacol. Res. 64, 195-202.

Xiang, Y.Z., Shang, H.C., Gao, X.M. and Zhang, B.L. (2008) A comparison of the ancient use of ginseng in traditional Chinese medicine with modern pharmacological experiments and clinical trials.
Phytother. Res. 22, 851-858.

Xue, J.-F., Liu, Z.-J., Hu, J.-F., Chen, H., Zhang, J.T. and Chen, N.-H. (2006) Ginsenoside Rb1 promotes neurotransmitter release by modulating phosphorylation of synapsins through a cAMPdependent protein kinase pathway. Brain Res. 1106, 91-98.

Yang, Y.-S., Ahn, T.-H., Lee, J.-C., Moon, C.-J., Kim, S.-H., Jun, W., Park, S.-C., Kim, H.-C. and Kim, J.-C. (2008) Protective effects of Pycnogenol ${ }^{\circledR}$ on carbon tetrachloride-induced hepatotoxicity in Sprague-Dawley rats. Food Chem. Toxicol. 46, 380-387.

Yoshioka, T., Kawada, K., Shimada, T. and Mori, M. (1979) Lipid peroxidation in maternal and cord blood and protective mechanism against activatedoxygen toxicity in the blood. Am. J. Obstet. Gynecol. 135, 372-376.

Zhang, H.A., Zhou, J., Lin, Y., Liu, H., Cui, Y., Xu, Y., Zhao, N., Ma, J., Fan, K. and Jiang, C. (2014) Protective effect of ginsenoside against acute renal failure via reduction of renal oxidative stress and enhanced expression of ChAT in the proximal convoluted tubule and ERK1/2 in the paraventricular nuclei. Physiol. Res. 63, 597.

Zhou, L. and Zhu, D.-Y. (2009) Neuronal nitric oxide synthase: structure, subcellular localization, regulation, and clinical implications. Nitric Oxide, 20, 223-230.

Zhu, D., Wu, L., Li, C.R., Wang, X.W., Ma, Y.J., Zhong, Z.y., Zhao, H.B., Cui, J., Xun, S.F. and Huang, X.L. (2009) Ginsenoside Rg1 protects rat cardiomyocyte from hypoxia/reoxygenation oxidative injury via antioxidant and intracellular calcium homeostasis. J. Cell. Biochem. 108, 117-124.

(Received 21/11/2017; accepted 10/3/2018) 


\section{مستخلص الجينسنج يحسن الأضرار الدماغية الناجمة عن أشعة جامـا في ذكور الجرذان \\ البيضاء \\ شيرين محمد الكيكى و شيرين محمد جلال الإل \\ قسم البحوث الصحيه الأشعاعية ـ المركز القومى لبحوث و تكنولوجيا الأشعاع ـ هيئة الطاقة الذريه ـالقاهرة-}

تهدف هذه الدراسة إلى التعرف على التأثير ات الوقائية لنبات الجينسنج ضد الأضر ار الدماغية الناجمة عن أشعة

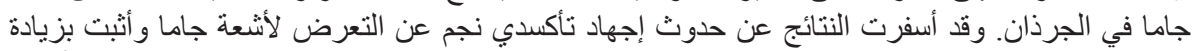

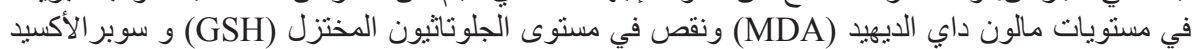

ديزموتيز (SOD) و الكتاليز (CAT) في نسيج المخ.

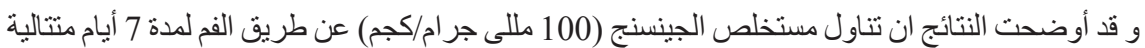

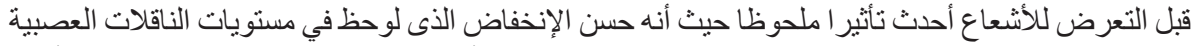

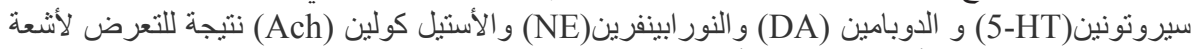

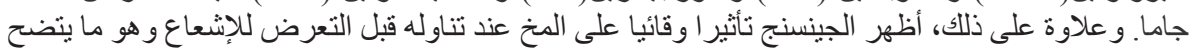

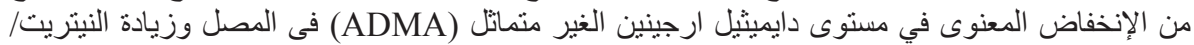

نترات (NO(x) مقارنة بالمجموعه المشععة و قد أكد الفحص النسيجي و المناعي التحسن المذكور في نتائج

القياسات البيوكيميائية.

ونستخلص من الدراسة بأن الجينسنج يلعب دورا وقائيا فعالا حيث أنه يخفة من التلف التأكسدي للألنسجه

الدماغية و الأضطر اب في مستويات الناقلات العصبية الناجم عن التعرض لأشعة جاما في الجرذان. 